\title{
Host knockout of E-prostanoid 2 receptors reduces tumor growth and causes major alterations of gene expression in prostaglandin $\mathbf{E}_{\mathbf{2}}$-producing tumors
}

\author{
ANNIKA GUSTAFSSON ASTING ${ }^{1}$, BRITT-MARIE IRESJÖ ${ }^{1}$, CAMILLA NILSBERTH ${ }^{2,3}$, \\ ULRIKA SMEDH $^{1}$ and KENT LUNDHOLM ${ }^{1}$
}

\begin{abstract}
${ }^{1}$ Department of Surgery, Institute of Clinical Sciences, Sahlgrenska Academy, University of Gothenburg, SE-413 45 Gothenburg; Departments of ${ }^{2}$ Geriatric Medicine and ${ }^{3}$ Clinical and Experimental Medicine, Linköping University, SE-581 85 Linköping, Sweden
\end{abstract}

Received August 12,2015; Accepted August 10, 2016

DOI: $10.3892 / \mathrm{ol} .2016 .5448$

\begin{abstract}
Prostaglandin $\mathrm{E}_{2}\left(\mathrm{PGE}_{2}\right)$ is elevated in a variety of malignant tumors and has been shown to affect several hallmarks of cancer. Accordingly, the $\mathrm{PGE}_{2}$ receptor, E-prostanoid 2 (EP2), has been reported to be associated with patient survival and reduced tumor growth in EP2-knockout mice. Thus, the aim of the present study was to screen for major gene expression alterations in tumor tissue growing in EP2-knockout mice. EP2-knockout mice were bred and implanted with EP2 receptor-expressing and $\mathrm{PGE}_{2}$-producing epithelial-like tumors. Tumor tissue and plasma were collected and used for analyses with gene expression microarrays and multiplex enzyme-linked immunosorbent assays. Tumor growth, acute phase reactions/systemic inflammation and the expression of interleukin-6 were reduced in EP2-knockout tumor-bearing mice. Several hundreds of genes displayed major changes of expression in the tumor tissue when grown in EP2-knockout mice. Such gene alterations involved several different cellular functions, including stemness, migration and cell signaling. Besides gene expression, several long non-coding RNAs were downregulated in the tumors from the EP2-knockout mice. Overall, $\mathrm{PGE}_{2}$ signaling via host EP2 receptors affected a large number of different genes involved in tumor progression based on signaling between host stroma and tumor cells, which caused reduced tumor growth.
\end{abstract}

Correspondence to: Dr Annika Gustafsson Asting, Department of Surgery, Institute of Clinical Sciences, Sahlgrenska Academy, University of Gothenburg, Bla Straket 5, SE-413 45 Gothenburg, Sweden

E-mail: annika.gustafsson@surgery.gu.se

Abbreviations: COX-1/2, cyclooxygenase-1/2; EP, E-prostanoid; FC, fold-change; lncRNA, long non-coding RNA; $\mathrm{PGE}_{2}$, prostaglandin $\mathrm{E}_{2}$

Key words: EP2 receptor, EP2-knockout, prostaglandin E2, cancer, tumor growth, cyclooxygenase

\section{Introduction}

Carcinogenesis is a multistep and multifactorial process in which inflammation is important. Clinical observations have indicated that the use of non-steroidal anti-inflammatory drugs (NSAIDs) may reduce tumor growth and development, and may improve patient survival $(1,2)$. The main effect of NSAIDs is the inhibition of cyclooxygenase (COX) enzymes, which exist in two isoforms, COX-1 and COX-2, and catalyze the conversion of arachidonic acid to prostanoids. Prostanoid-promoted tumor growth and subsequent host survival are driven by the signaling of prostaglandin $\mathrm{E}_{2}\left(\mathrm{PGE}_{2}\right)$, which acts via E-prostanoid 1-4 (EP1-4) subtype receptors (3).

It is well-recognized that $\mathrm{COX}-2 / \mathrm{PGE}_{2}$ signaling involves several different processes of tumor progression, including the inhibition of apoptosis, increased angiogenesis and metastatic formation (4). Thus, the actions of $\mathrm{PGE}_{2}$ depend on the pattern or mix of EP receptor expression in normal and cancer cells, since each receptor promotes distinctive downstream signaling. In a previous study on human colorectal cancer, we reported high levels of EP1 and EP2 receptor protein in human tumor tissue, with considerably less content in the stroma. In the same study, EP3 receptor protein occurred mostly in the submucosa of such tumors and occasionally in the tumor cells, while EP4 receptor protein was usually not visible at all in the human colorectal tumor cells (5). It was also found that disease-specific mortality in colorectal cancer showed a negative correlation with EP2 receptor expression $(5,6)$. Moreover, several studies have displayed that EP2-knockout mice have reduced tumor growth compared with tumors in wild-type mice (7-11). Therefore, we speculate that the differences in gene expression among tumors growing on EP2-knockout mice versus tumors growing on wild-type mice may indicate important signaling between the tumor and stroma tissue, which subsequently determines tumor growth and progression. Thus, the aim of the present study was to screen for potentially important transcript alterations in tumor tissue associated with host EP2 receptor signaling. 


\section{Materials and methods}

Animals. The animal experimental protocol was approved by the Committee for Ethics at the University of Gothenburg (Gothenburg, Sweden). Adult, male and female (6-7-month-old, 20 $\pm 1 \mathrm{~g})$ age-matched EP2 $2^{-/-}(\mathrm{n}=7)$ and EP2 $2^{+/+}$ $(n=8)$ mice (C57BL/6 genetic backgrounds) were in-house bred (12) and housed in plastic cages in a temperature controlled room with a $12 \mathrm{~h}$ dark/light cycle, and received laboratory rodent chow (B\&K Universal AB, Stockholm, Sweden). Tumors were implanted subcutaneously in the bilateral flanks with a $3-5-\mathrm{mm}^{3}$ syringe containing a transplantable MCG-101 methylcholanthrene-induced sarcoma while the mice were under general anesthesia (isoflurane, inhaled concentration of $2.7 \%$ ). This tumor model has been used for several years at the Department of Surgery, University of Gothenburg (Gothenburg, Sweden) and is known to produce increased levels of $\mathrm{PGE}_{2}$ in the systemic circulation (10). The model originates from a chemically induced tumor on C57BL mice and appears now to be an epithelial-like poorly-differentiated tumor. All mice were sacrificed on day 10 post-tumor implantation, when blood samples were obtained during general anesthesia by cardiac puncture for plasma $\mathrm{PGE}_{2}$ determination and additional analyses. Plasma samples were collected in ethylenediaminetetraacetic acid tubes and stored at $-80^{\circ} \mathrm{C}$ until use. Tumor biopsies were collected in RNA-later according to the manufacturer's protocols (Sigma-Aldrich; Merck Millipore, Darmstadt, Germany). Wet tumor weight was determined by direct weighing immediately upon resection.

Plasma analysis. Multiplex enzyme-linked immunosorbent assays (Luminex ${ }^{\circledR}$; Merck KGaA, Darmstadt ,Germany) were performed on plasma samples from the EP2-knockout mice and wild-type mice using two different panels: i) Mouse acute phase magnetic bead panel 2 with antibodies towards serum amyloid protein/pentraxin-2 (SAP), adipsin (complement factor D), $\alpha$-2-macroglobulin (A2M) and haptoglobin; and ii) a mouse cytokine magnetic bead panel with antibodies towards IL-1 $\alpha$, IL-1 $\beta$, IL-6, IL-10, tumor necrosis factor $\alpha$ (TNF $\alpha$ ), vascular endothelial growth factor and interferon $\gamma$ $($ IFN $\gamma)\left(\right.$ Milliplex ${ }^{\circledR}$ Map; Merck KGaA). Analyses were performed according to the manufacturer's protocols for plasma samples and all samples were run in duplicate; plasma samples used for the acute phase panel were diluted 1:1,000 in assay buffer and those for the cytokine panel were diluted $1: 2$ in assay buffer.

Tumor analysis: RNA extraction. Total RNA was extracted from tumor tissue using an RNeasy Fibrous Tissue kit according to the manufacturer's protocols (Qiagen $\mathrm{GmbH}$, Hilden, Germany). The quality and quantity of RNA were checked in an Agilent 2100 Bioanalyzer using an RNA 6000 Nano assay kit with an RNA Integrity number of 7 as the limit for further analyses (Agilent Technologies, Inc., Santa Clara, CA, USA). Concentrations of RNA were measured in a NanoDrop ND-1000A spectrophotometer (NanoDrop Technologies, Inc.; Thermo Fisher Scientific, Inc., Wilmington, DE, USA). RNA from the wild-type mice $(n=8)$ was pooled and used as reference RNA in the gene expression analyses.

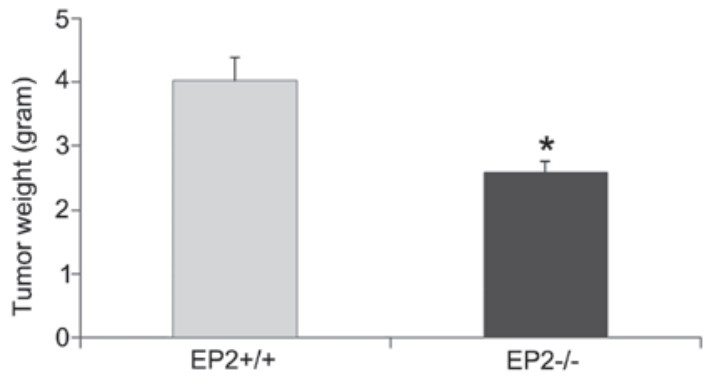

Figure 1. Tumor wet weight in EP2-knockout mice (-/-) versus wild-type mice $(+/+)$ at 10 days post-tumor implantation $\left[\mathrm{EP} 2^{-/-}(\mathrm{n}=7), 2.6 \pm 0.17 ; \mathrm{EP} 2^{+/+}\right.$ $\left.(\mathrm{n}=8), 4.0 \pm 0.36 ;{ }^{*} \mathrm{P}<0.05\right]$. EP2, E-prostanoid 2.

Tumor analysis: Gene expression microarray. Microarray analyses were performed on 7 biological replicates of tumor mRNA from $\mathrm{EP}^{-/-}$mice, with pooled wild-type RNA as reference RNA. mRNA (500 ng) from the tumors was labeled with Cy-3-dCTP in a cDNA synthesis reaction with Agilent Flourescent Direct Label (Agilent Technologies, Inc.). Pooled wild-type tumor RNA samples (500 ng) were labeled with Cy-5-dCTP. The samples were then hybridized using a SurePrint G3 Mouse GE 8x60K Microarray kit, design ID 028005 [detects 4,623 long non-coding RNAs (lncRNAs); Agilent Technologies, Inc.] according to the manufacturer's instructions. Microarrays were quantified on an Agilent G2505C microarray scanner and fluorescence intensities were extracted using the Feature Extraction software program (v10.7.1.1; Agilent Technologies, Inc.). Dye-normalized, outlier- and background-subtracted values were analyzed in the GeneSpring GX10 software program (Agilent Technologies, Inc.) according to standard procedures. Quality control was performed with QC metrics. A fold-change (FC) of $>1.5$ of $\log 2$-transformed ratios was considered a statistically significant change in gene expression. The analyses used were 'filter on flags' (present or marginal) and the t-test $(\mathrm{P}<0.05)$. The results are presented as the mean FC value of 7 replicates.

Statistical analysis. Statistical analyses were performed with StatView for Windows version 5.0.1 (SAS institute Inc., Cary, $\mathrm{NC}$, USA). The results are presented as the mean \pm standard error of the mean. Cytokine and acute phase results were analyzed with an analysis of variance followed by Fisher's protected least significant difference test. $\mathrm{P} \leq 0.05$ was considered to indicate a statistically significant difference in two-tailed tests.

\section{Results}

Tumor growth and systemic inflammation. Tumor growth in the EP2 $2^{-/}$mice was significantly reduced compared with tumor growth in the wild-type mice at 10 days post-tumor implantation (Fig. 1). No significant difference in plasma $\mathrm{PGE}_{2}$ was detected between the EP2-knockout and wild-type mice, as previously reported (10). Systemic inflammation was decreased in the EP2 $2^{-/}$mice, as displayed by significantly reduced levels of the acute phase proteins A2M and SAP in the blood (Fig. 2). The cytokine assay displayed non-detectable 
Table I. Significantly changed number of lncRNAs per chromosome in tumors from E-prostanoid $2^{-/}$mice compared with tumors from wild-type mice.

\begin{tabular}{cccc}
\hline Chromosome & FC 2.0 & FC 5.0 & FC 10 \\
\hline 1 & $21 \downarrow, 24 \uparrow$ & $2 \downarrow$ & $1 \downarrow$ \\
2 & $26 \downarrow, 14 \uparrow$ & $3 \downarrow$ & - \\
3 & $39 \downarrow, 12 \uparrow$ & - & - \\
4 & $35 \downarrow, 12 \uparrow$ & - & - \\
5 & $34 \downarrow, 11 \uparrow$ & $3 \downarrow$ & $2 \downarrow$ \\
6 & $25 \downarrow, 12 \uparrow$ & - & - \\
7 & $20 \downarrow, 8 \uparrow$ & $1 \downarrow$ & - \\
8 & $25 \downarrow, 17 \uparrow$ & $2 \downarrow$ & - \\
9 & $26 \downarrow, 6 \uparrow$ & $2 \downarrow$ & - \\
10 & $21 \downarrow, 15 \uparrow$ & $1 \downarrow$ & - \\
11 & $21 \downarrow, 16 \uparrow$ & - & - \\
12 & $19 \downarrow, 8 \uparrow$ & - & - \\
13 & $24 \downarrow, 7 \uparrow$ & $2 \downarrow$ & $1 \downarrow$ \\
14 & $21 \downarrow, 12 \uparrow$ & - & - \\
15 & $15 \downarrow, 14 \uparrow$ & - & - \\
16 & $20 \downarrow, 9 \uparrow$ & $1 \downarrow$ & - \\
17 & $13 \downarrow, 12 \uparrow$ & - & - \\
18 & $17 \downarrow, 7 \uparrow$ & - & - \\
19 & $11 \downarrow, 7 \uparrow$ & $1 \downarrow$ & - \\
$20^{\mathrm{a}}$ & - & - & - \\
$21^{\mathrm{a}}$ & - & - & - \\
$22^{\mathrm{a}}$ & - & - & - \\
$\mathrm{X}$ & $32 \downarrow, 10 \uparrow$ & $1 \downarrow$ & - \\
$\mathrm{Y}$ & - & - & - \\
\hline
\end{tabular}

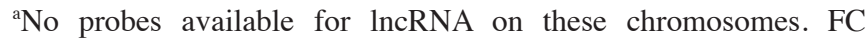
fold-change; lncRNA, long non-coding RNA; $\uparrow$, upregulated; $\downarrow$, downregulated.

levels $(<3.2 \mathrm{ng} / \mathrm{ml})$ of IL-1 $\beta$ (in 6 out of 15 mice), IFN $\gamma$ (in 12 out of 15 mice), IL-10 (in 13 out of 15 mice) and TNFa (in 11 out of 15 mice), while IL- 6 was detected in all samples and was significantly reduced in plasma from $\mathrm{EP}^{-/}$mice (Fig. 3). Non-tumor-bearing animals showed no signs of acute phase reactions $(13,14)$.

Tumor gene expression. A total of 55,821 gene expression microarray entities passed the 'filter on flags' analysis, while 16,127 entities exhibited significant alterations upon t-test $(\mathrm{P}<0.05)$. Results displayed the changed expression of several genes as well as lncRNA expression (Table I). At 2-fold change [FC 2], several entities were changed; 1,685 genes and 234 lncRNA were upregulated while 800 genes and 465 lncRNA were downregulated. Increasing $\mathrm{FC}$, representing greater differences, indicated a trend towards downregulation in the knockout mice. At FC 5, 153 entities were downregulated, and at FC 10, 7 genes and 7 lncRNAs were downregulated compared with the tumors in the wild-type mice. Genes with highly changed expression were associated with a range of different cellular functions (Table II).

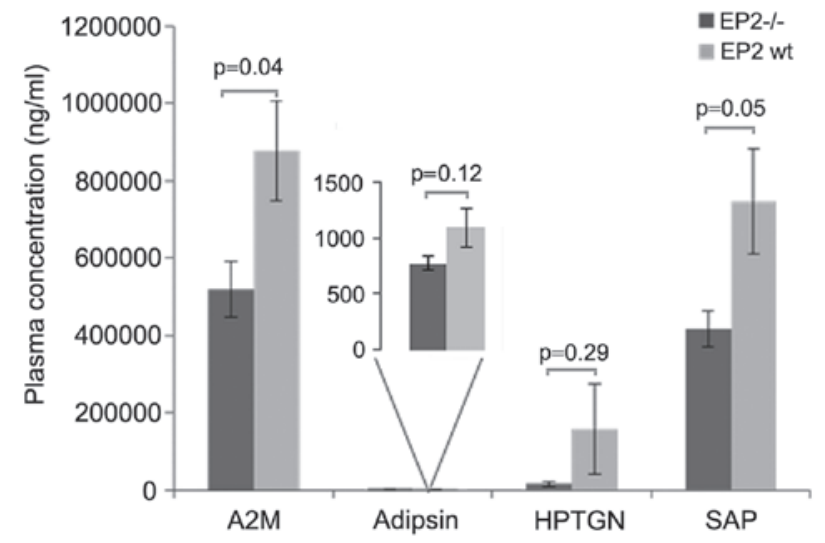

Figure 2. Systemic inflammation was decreased in EP2 $2^{-/-}$tumor-bearing mice compared with wild-type mice, as reflected by plasma levels (ng/ml) of A2M and SAP, and determined by the acute phase Luminex ${ }^{\circledR}$ assay $\left(\mathrm{EP} 2^{-/}, \mathrm{n}=7\right.$; $\mathrm{EP} 2^{+/+}, \mathrm{n}=8$ ). EP2, E-prostanoid 2; A2M, $\alpha$-2-macroglobulin; SAP, serum amyloid protein/pentraxin-2; HPTGN, haptoglobin.

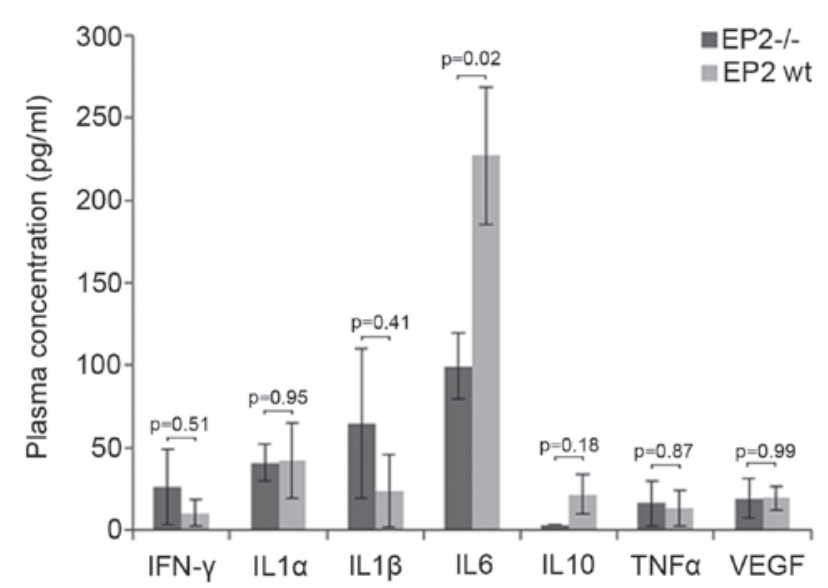

Figure 3. Plasma concentrations of cytokines in EP2-knockout and wild-type tumor-bearing mice. Levels of IL6 $(\mathrm{pg} / \mathrm{ml})$ were significantly reduced in $\mathrm{EP}^{-/-}$mice $\left(\mathrm{EP}^{-/}, \mathrm{n}=7 ; \mathrm{EP} 2^{+/+}, \mathrm{n}=8\right)$. EP2, E-prostanoid 2; IL, interleukin; IFN, interferon; TNF, tumor necrosis factor; VEGF, vascular endothelial growth factor.

$\mathrm{PGE}_{2}$-related transcripts were significantly changed in the tumor tissues from the EP2 $2^{--}$mice (Table III); Cox-1 and 15-hydroxyprostaglandin dehydrogenase (15-Pgdh) expression was upregulated, while Cox-2 expression was downregulated. EP subtype receptors were upregulated, except EP3, in tumors on EP2 $2^{-/-}$mice, particularly EP2 receptor (Ptger2; FC 7.9). Another prostanoid receptor with highly changed expression was Ppara $(\mathrm{PPAR} \alpha)$, which was 4-fold downregulated.

Genes associated with tumor progression, including stemness [cluster of differentiation 133/ prominin-1 (Cd133/Prom1) and $C d 44$ ], displayed decreased expression in the tumor tissue of the EP2 $2^{--}$mice, while the majority of cytokines $(I l l b, I l 6$, IllO and Ifng) and metalloproteinase 13 (Mmpl3) showed increased expression (Table IV). Only genes with significantly changed expression are reported in Table IV. Other genes that may be important for tumor progression did not show significantly altered expression, including TNF $\alpha(T f a b 2 a), N f \kappa b$, Nfat and Ras-family transcripts. 
Table II. Genes with the most changed expression in tumor tissue from EP2 $2^{-/}$mice versus tumors in wild-type mice.

\begin{tabular}{|c|c|c|c|}
\hline Gene & Regulation & FC & Name/known function \\
\hline $\mathrm{Npl}$ & $\uparrow$ & 9.4 & $\mathrm{~N}$-acetylneuraminate pyruvate lyase \\
\hline Ptplad2 & $\uparrow$ & 8.6 & Protein tyrosine phosphatase-like A domain-containing 2 \\
\hline Ptger2 & $\uparrow$ & 7.9 & $\mathrm{PGE}_{2}$ receptor EP2 \\
\hline Ear11 & $\uparrow$ & 7.6 & Ribonuclease, RNase $2 \mathrm{~A}$ \\
\hline Gm5150 & $\uparrow$ & 7.0 & Predicted gene 5150 , protein coding \\
\hline Slc40al & $\uparrow$ & 6.8 & Solute carrier family 40 (iron-regulated transporter) \\
\hline$C y b b$ & $\uparrow$ & 6.6 & $\begin{array}{l}\text { Cytochrome b-245, important in the innate immune response, } \\
\text { increased activity leads to the generation of reactive oxygen } \\
\text { species that result in oxidative stress and can cause tissue damage. }\end{array}$ \\
\hline Dock10 & $\uparrow$ & 6.5 & Dedicator of cytokinesis 10 \\
\hline Gstm5 & $\uparrow$ & 6.5 & Glutathione S-transferase \\
\hline$C d 79 b$ & $\uparrow$ & 6.4 & CD79B antigen also known as $\mathrm{B} 29, \operatorname{Igb}, \operatorname{Ig} \beta$ or $\operatorname{Ig}-\beta$ \\
\hline Cpne5 & $\downarrow$ & 16.0 & $\begin{array}{l}\text { May regulate molecular events at the interface of the cell } \\
\text { membrane and cytoplasm }\end{array}$ \\
\hline Krtl8 & $\downarrow$ & 14.9 & Protects epithelial tissue from injury \\
\hline Tnfrsfl3b & $\downarrow$ & 12.7 & TNF receptor superfamily, regulation of B cell function \\
\hline Fndc7 & $\downarrow$ & 12.3 & Fibronectin type III \\
\hline Lrit1 & $\downarrow$ & 12.0 & $\begin{array}{l}\text { Leucine-rich repeat, immunoglobulin-like transmembrane } \\
\text { domains } 1\end{array}$ \\
\hline Spespl & $\downarrow$ & 10.6 & Required for fully fertile sperm in mice \\
\hline Sntgl & $\downarrow$ & 10.0 & Syntrophins are cytoplasmic peripheral membrane proteins \\
\hline Vmn2r69 & $\downarrow$ & 9.9 & Vomeronasal 2, receptor 69, Vomeronasal organ \\
\hline Rn18s & $\downarrow$ & 8.7 & $18 \mathrm{~S}$ ribosomal RNA \\
\hline Slc7a15 & $\downarrow$ & 8.7 & Solute carrier family 7 (cationic amino acid transporter) \\
\hline
\end{tabular}

FC, fold-change; $\uparrow$, upregulated; $\downarrow$, downregulated; EP2, E-prostanoid 2; PGE 2 , CD, cluster of differentiation; Ig, immunoglobulin; TNF, tumor necrosis factor.

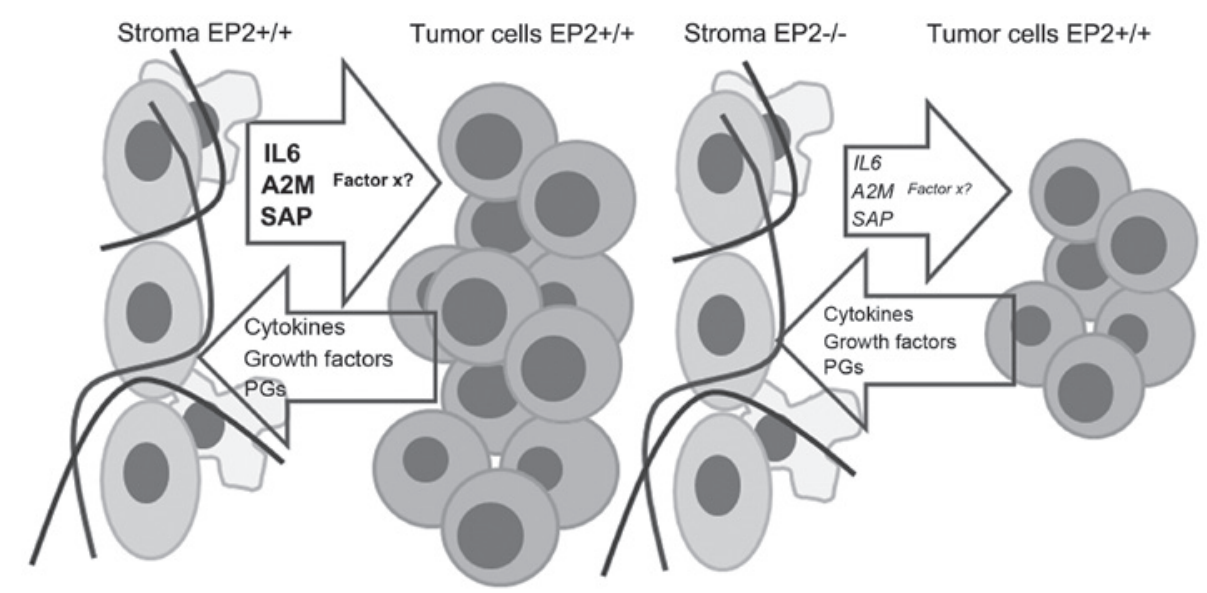

Figure 4. Summary of a speculative interpretation of the findings in the present study, as well as knowledge from the literature. Host EP2-knockout reduced systemic inflammation and plasma cytokine levels, as well as tumor gene expression, resulting in significantly reduced tumor growth in the EP2-knockout mice. These alterations indicated that stroma-tumor interactions based on IL- 6 and inflammatory signaling were important for tumor growth, perhaps associated with an undiscovered 'factor x', as suggested by the present illustration. EP2, E-prostanoid 2; A2M, $\alpha$-2-macroglobulin; SAP, serum amyloid protein/ pentraxin-2; HPTGN, haptoglobin; IL, interleukin.

\section{Discussion}

The elevated production of $\mathrm{PGE}_{2}$ has been linked to tumor progression in numerous types of cancer, and reduced $\mathrm{PGE}_{2}$ activities with COX-inhibiting NSAIDs have been reported to reduce tumor growth in animal models, as well as in clinical studies $(4-6,15,16)$. However, the non-specific drug inhibition of COX can also induce adverse side effects $(4-6,15,16)$. 
Table III. Effect of host EP2 $2^{-/-}$on prostanoid-related transcripts in tumor tissue. ${ }^{\mathrm{a}}$

\begin{tabular}{|c|c|c|c|}
\hline Gene & Enzyme/receptor & $\mathrm{FC}$ & Regulation \\
\hline \multicolumn{4}{|l|}{ PG metabolism } \\
\hline Ptgsl & COX-1 & 2.6 & $\uparrow$ \\
\hline Ptgs 2 & $\mathrm{COX}-2$ & 1.5 & $\downarrow$ \\
\hline Hpgd & 15-PGDH & 3.1 & $\uparrow$ \\
\hline$P g t$ & PGT & 2.1 & $\downarrow$ \\
\hline Mrp4 & MRP4 & - & - \\
\hline \multicolumn{4}{|l|}{$\mathrm{PGE}_{2}$} \\
\hline Ptges & mPGES-1 & 1.5 & $\downarrow$ \\
\hline Ptges 2 & mPGES-2 & - & - \\
\hline Ptges3 & cPGES & - & - \\
\hline Ptgerl & EP1 receptor & 1.7 & $\uparrow$ \\
\hline Ptger 2 & EP2 receptor & 7.9 & $\uparrow$ \\
\hline Ptger3 & EP3 receptor & 3.7 & $\downarrow$ \\
\hline Ptger4 & EP4 receptor & 3.2 & $\uparrow$ \\
\hline \multicolumn{4}{|l|}{$\mathrm{PGD}_{2}$} \\
\hline Ptgds & PGD2 synthase & - & - \\
\hline$P t g d r$ & DP1 receptor & 1.5 & $\downarrow$ \\
\hline Gpr44 & DP2 receptor & - & - \\
\hline \multicolumn{4}{|l|}{$\mathrm{PGF}_{2 \alpha}$} \\
\hline 2810405K02Rik & PGF synthase & 2.1 & $\uparrow$ \\
\hline Ptgfr & FP receptor & 2.0 & $\uparrow$ \\
\hline Ptgfrn & Neg. regulator PGF2 & 1.5 & $\uparrow$ \\
\hline \multicolumn{4}{|l|}{$\mathrm{PGI}_{2}$} \\
\hline Ptgis & PGI synthase & - & - \\
\hline Ptgir & IP receptor & 1.8 & $\uparrow$ \\
\hline \multicolumn{4}{|l|}{$\mathrm{TXA}_{2}$} \\
\hline Tbxas1 & TXA synthase & 3.1 & $\uparrow$ \\
\hline$T b x a 2 r$ & TP receptor & 1.7 & $\uparrow$ \\
\hline \multicolumn{4}{|l|}{ Nuclear receptors } \\
\hline Ppara & $\operatorname{PPAR} \alpha$ receptor & 4.3 & $\downarrow$ \\
\hline Ppard & 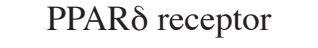 & - & - \\
\hline Pparg & $\operatorname{PPAR} \gamma$ receptor & - & - \\
\hline
\end{tabular}

${ }^{\mathrm{a}} \mathrm{FC} 1.5$ was regarded as significantly changed compared with the tumor tissue from wild-type mice, $\mathrm{P}<0.05$. FC, fold-change; $\uparrow$, upregulated; $\downarrow$, downregulated; COX, cyclooxygenase; EP, E-prostanoid.

Therefore, it is of interest to find more specific targets to inhibit the actions of prostaglandins in cancer. $\mathrm{PGE}_{2}$ activates subtype receptors, EP1-4, which induce downstream signaling upon activation. EP2 receptor signaling is involved in several different physiological and disease-related events, which are of interest in targeted therapy (17). In tumors, EP2 and EP4 have gained the most attention, as tumor-host knockout models have been shown to display reduced tumor growth $(7,18)$. Previous studies have focused on polyp formation, proliferation, apoptosis and angiogenesis, while the present study evaluated overall transcription in tumor cells (7-9,19-22). Indeed, tumor growth was significantly reduced in the present EP2-knockout tumor-bearing mice where the host lacked EP2 expression,
Table IV. Transcripts of genes associated with tumor progression, transcription and cancer stemness that were significantly changed in tumor tissue from EP2 $2^{-/-}$mice. ${ }^{a}$

\begin{tabular}{|c|c|c|}
\hline Gene & $\mathrm{FC}$ & Regulation \\
\hline \multicolumn{3}{|l|}{ Cytokines } \\
\hline$I L 1 B$ & 2.1 & $\uparrow$ \\
\hline IL6 & 2.8 & $\uparrow$ \\
\hline$I L 6 R$ & 1.6 & $\downarrow$ \\
\hline IL10 & 1.9 & $\uparrow$ \\
\hline ILIORA & 2.2 & $\uparrow$ \\
\hline$I F N g$ & 2.3 & $\uparrow$ \\
\hline \multicolumn{3}{|l|}{ Stemness } \\
\hline CD133/Prom1 & 1.5 & $\downarrow$ \\
\hline$C D 44$ & 1.9 & $\downarrow$ \\
\hline \multicolumn{3}{|c|}{ Tumor progression } \\
\hline Mmpl3 & 6.1 & $\uparrow$ \\
\hline Mmp7 & 1.5 & $\downarrow$ \\
\hline Hifla & 1.8 & $\uparrow$ \\
\hline Dnmt3a & 1.6 & $\downarrow$ \\
\hline$A p c$ & 1.5 & $\downarrow$ \\
\hline Gsk3b & 1.6 & $\downarrow$ \\
\hline Egfr & 2.0 & $\uparrow$ \\
\hline Prkcb & 2.9 & $\uparrow$ \\
\hline \multicolumn{3}{|l|}{ Transcription } \\
\hline Batf & 3.5 & $\uparrow$ \\
\hline Cebpa & 3.4 & $\uparrow$ \\
\hline Creb5 & 1.9 & $\downarrow$ \\
\hline Fos & 2.7 & $\uparrow$ \\
\hline$T c f 4$ & 1.8 & $\downarrow$ \\
\hline
\end{tabular}

${ }^{a} \mathrm{FC} 1.5$ was regarded as significantly changed compared with the tumor tissue from wild-type mice, $\mathrm{P}<0.05$. $\uparrow$, upregulated; $\downarrow$, downregulated; FC, fold-change.

while tumor cells displayed EP2 receptor expression. Thus, a response circuit between host and tumor cells appears to be interrupted by a lack of EP2 signaling from the host stroma, as illustrated in Fig. 4. The systemic effects in tumor-bearing EP2-knockout mice were reduced inflammation and a reduced plasma IL-6 level, as expected. Accordingly, inflammation and inflammatory factors, such as IL-6, have been recognized to drive tumor progression (23), which may be one of several factors behind reduced tumor growth in EP2 receptor-knockout mice. IL-6 and $\mathrm{PGE}_{2}$ have been shown to affect the epithelial-to-mesenchymal transition (EMT) in tumor cells via the EP2 and EP4 receptors (23). Also, EMT was shown to affect the expression of EP subtype receptors in human bronchial epithelial cells with reduced EP2, EP4 and one of the EP3 subtype receptors (24). In the same study, an altered response to $\mathrm{PGE}_{2}$ regarding cell migration was detected after EMT from stimulation to inhibition, mediated by EP2 and EP4 receptors (24).

In the present study, several hundreds of genes showed changed expression in the tumor tissues from the 
EP2-knockout mice compared with tumor tissues from the wild-type mice. A reason for this could be that EP2 signaling in host tissues is involved in several different pathways that are important events in tumor cells associated with tumor progression, including angiogenesis, the upregulation of COX-2, the loss of E-cadherin expression and anti-apoptosis in stem cells $(16,22,25-28)$. Prom-1, also known as CD133, and CD44 are well-known markers of cancer stem cells, indicating reduced gene expression in the tumor tissues from the EP2-knockout mice in the present study. This suggests that $\mathrm{PGE}_{2}$ and EP2 receptor signaling may be involved in tumor progression associated with cancer stem cells. In agreement with this, our earlier study reported that pre-operative COX inhibition with NSAIDs reduced the expression levels of stemness factors (CD133) in human colon cancer tissue (16).

Ptger 2 transcripts were increased almost 8 -fold in the tumors of the EP2-knockout mice, probably due to a changed feedback-loop between COX-2, PGE 2 and EP2 (7). G-proteins start signaling via protein kinase $\mathrm{A}$ and $\mathrm{CREB}$ mainly upon activation of EP2 by $\mathrm{PGE}_{2}$. This phenomenon has been reported to be a $\mathrm{PGE}_{2}$-dependent pathway for cell proliferation and COX-2 induction (21). Creb and Cox-2 gene expression were downregulated in the tumors from the EP2-knockout mice in the present study. By contrast, Cox-1 and 15-Pgdh were upregulated. COX-1 has similar effects as COX-2 in tumor models $(29,30)$, while 15-PGDH degrades prostaglandins. The transporter of prostaglandins across cell membranes was also downregulated in the tumors from the EP2-knockout mice in the present study. This could result in reduced levels of $\mathrm{PGE}_{2}$ in tumors from EP2-knockout mice, which may explain the increase in EP receptor transcripts, as well as the reduced tumor growth.

Other genes involved in tumor progression that displayed changed expression in the tumors of the EP2-knockout mice were hypoxia inducible factor $1 \alpha$ subunit (Hifla) and metalloproteinases (Mmps). Hifla was 1.83-fold upregulated in the knockout mice, even when the tumors were small. A previous study reported that HIF- $1 \alpha$ is upregulated by $\mathrm{PGE}_{2}$, contributing to metastasis and chemoresistance, as well as the promotion of prostate cancer cell migration, invasion and angiogenesis (31). Mmps degrade extracellular matrix and facilitate the migration of tumor cells. In the present study, Mmp-13 gene expression was 6-fold upregulated in the tumors from the EP2-knockout mice, with reduced tumor growth. EP2 signaling has been shown to inhibit the production of MMP-13 in human osteoarthritic chondrocytes (32) and EP2 may be involved in the regulation of MMPs.

Several lncRNAs showed different expression in the tumor-bearing EP2 receptor-knockout mice in the present study. The function of numerous lncRNAs is not known, but in general, lncRNAs are involved in the regulation of downstream gene expression (33). This is a novel area of research and the results require further investigation. It is not known to what extent changed lncRNAs are conserved between mice and humans. In general, lncRNAs lack strong conservation, although several transcripts have conserved elements $(34,35)$. It is well recognized that mouse models do not completely reflect human conditions, particularly with regard to inflammation (36). However, human and mouse EP2 receptors have $88 \%$ identity and differ at the $\mathrm{NH}_{2}$ terminus, where the mouse receptor has 25 extra amino acids. Additionally, the pharmacological properties of human EP2 are similar to those of mouse EP2 receptors (37).

Overall, in the present study, EP2 receptor-knockout in tumor-bearing host tissues reduced tumor growth, systemic inflammation and IL-6 expression, which affected the expression of several hundred genes and lncRNAs in tumor tissue. Thus, altered signaling from the host affected tumor growth with attenuation of $\mathrm{PGE}_{2}$-related factors, since tumor cells from the EP2-knockout and wild-type mice possessed the same intrinsic gene equipment; Cox-1 and 15-Pgdh expression was upregulated, Cox-2 expression was downregulated and EP2 receptor gene expression was increased in the tumors from the EP2-knockout mice.

\section{Acknowledgements}

This study was supported by grants from the Swedish Cancer Society (no. CAN 2010/255), the Swedish State under the LUA/ALF agreement, the Assar Gabrielsson foundation and the Magnus Bergvall foundation. The authors would like to acknowledge the expert technical skill of Dr Marianne Andersson, Dr Ludmila Mackerlova and the BEA Core Facility at the Karolinska Institute (Stockholm, Sweden).

\section{References}

1. Rothwell PM, Fowkes FG, Belch JF, Ogawa H, Warlow CP and Meade TW: Effect of daily aspirin on long-term risk of death due to cancer: Analysis of individual patient data from randomised trials. Lancet 377: 31-41, 2011.

2. Rothwell PM, Wilson M, Elwin CE, Norrving B, Algra A, Warlow CP and Meade TW: Long-term effect of aspirin on colorectal cancer incidence and mortality: 20-year follow-up of five randomised trials. Lancet 376: 1741-1750, 2010.

3. Greenhough A, Smartt HJ, Moore AE, Roberts HR, Williams AC, Paraskeva $\mathrm{C}$ and Kaidi A: The COX-2/PGE2 pathway: Key roles in the hallmarks of cancer and adaptation to the tumour microenvironment. Carcinogenesis 30: 377-386, 2009.

4. Wang D and Dubois RN: Eicosanoids and cancer. Nat Rev Cancer 10: 181-193, 2010.

5. Gustafsson A, Hansson E, Kressner U, Nordgren S, Andersson M, Wang W, Lönnroth C and Lundholm K: EP1-4 subtype, COX and PPAR gamma receptor expression in colorectal cancer in prediction of disease-specific mortality. Int J Cancer 121: 232-240, 2007.

6. Gustafsson A, Hansson E, Kressner U, Nordgren S, Andersson M, Lönnroth $\mathrm{C}$ and Lundholm K: Prostanoid receptor expression in colorectal cancer related to tumor stage, differentiation and progression. Acta Oncol 46: 1107-1112, 2007.

7. Sonoshita M, Takaku K, Sasaki N, Sugimoto Y, Ushikubi F, Narumiya S, Oshima $\mathrm{M}$ and Taketo MM: Acceleration of intestinal polyposis through prostaglandin receptor EP2 in Apc(Delta 716) knockout mice. Nat Med 7: 1048-1051, 2001.

8. Seno H, Oshima M, Ishikawa TO, Oshima H, Takaku K, Chiba T, Narumiya S and Taketo MM: Cyclooxygenase 2- and prostaglandin $\mathrm{E}(2)$ receptor $\mathrm{EP}(2)$-dependent angiogenesis in Apc (Delta716) mouse intestinal polyps. Cancer Res 62: 506-511, 2002.

9. Keith RL, Geraci MW, Nana-Sinkam SP, Breyer RM, Hudish TM, Meyer AM, Malkinson AM and Dwyer-Nield LD: Prostaglandin E2 receptor subtype 2 (EP2) null mice are protected against murine lung tumorigenesis. Anticancer Res 26: 2857-2861, 2006.

10. Iresjö BM, Wang W, Nilsberth C, Andersson M, Lönnroth C and Smedh U: Food intake, tumor growth, and weight loss in EP2 receptor subtype knockout mice bearing PGE2-producing tumors. Physiol Rep 3: e12441, 2015.

11. Ma X, Aoki T, Tsuruyama T and Narumiya S: Definition of prostaglandin E2-EP2 signals in the colon tumor microenvironment that amplify inflammation and tumor growth. Cancer Res 75: 2822-2832, 2015 
12. Tilley SL, Audoly LP, Hicks EH, Kim HS, Flannery PJ, Coffman TM and Koller BH: Reproductive failure and reduced blood pressure in mice lacking the EP2 prostaglandin E2 receptor. J Clin Invest 103: 1539-1545, 1999.

13. Andersson C, Gelin J, Iresjö BM and Lundholm K: Acute-phase proteins in response to tumor growth. J Surg Res 55: 607-614, 1993.

14. Gelin JL, Moldawer LL, Iresjö BM and Lundholm KG: The role of the adrenals in the acute phase response to interleukin-1 and tumor necrosis factor-alpha. J Surg Res 54: 70-78, 1993

15. Lundholm K, Gelin J, Hyltander A, Lönnroth C, Sandström R, Svaninger G, Körner U, Gülich M, Kärrefors I, Norli B, et al: Anti-inflammatory treatment may prolong survival in undernourished patients with metastatic solid tumors. Cancer Res 54: 5602-5606, 1994.

16. Lönnroth $\mathrm{C}$, Andersson $\mathrm{M}$, Asting AG, Nordgren $\mathrm{S}$ and Lundholm K: Preoperative low dose NSAID treatment influences the genes for stemness, growth, invasion and metastasis in colorectal cancer. Int J Oncol 45: 2208-2220, 2014.

17. Ganesh T: Prostanoid receptor EP2 as a therapeutic target. J Med Chem 57: 4454-4465, 2014

18. Mutoh M, Watanabe K, Kitamura T, Shoji Y, Takahashi M, Kawamori T, Tani K, Kobayashi M, Maruyama T, Kobayashi K, et al: Involvement of prostaglandin E receptor subtype $\mathrm{EP}(4)$ in colon carcinogenesis. Cancer Res 62: 28-32, 2002.

19. Brouxhon S, Konger RL, VanBuskirk J, Sheu TJ, Ryan J, Erdle B, Almudevar A, Breyer RM, Scott G and Pentland AP: Deletion of prostaglandin E2 EP2 receptor protects against ultraviolet-induced carcinogenesis, but increases tumor aggressiveness. J Invest Dermatol 127: 439-446, 2007.

20. Sung YM, He G and Fischer SM: Lack of expression of the EP2 but not EP3 receptor for prostaglandin E2 results in suppression of skin tumor development. Cancer Res 65: 9304-9311, 2005.

21. Ansari KM, Sung YM, He G and Fischer SM: Prostaglandin receptor EP2 is responsible for cyclooxygenase-2 induction by prostaglandin E2 in mouse skin. Carcinogenesis 28: 2063-2068, 2007.

22. Kamiyama M, Pozzi A, Yang L, DeBusk LM, Breyer RM and Lin PC: EP2, a receptor for PGE2, regulates tumor angiogenesis through direct effects on endothelial cell motility and survival. Oncogene 25: 7019-7028, 2006.

23. Li HJ, Reinhardt F, Herschman HR and Weinberg RA: Cancer-stimulated mesenchymal stem cells create a carcinoma stem cell niche via prostaglandin E2 signaling. Cancer Discov 2: 840-855, 2012.

24. Li YJ, Kanaji N, Wang XQ, Sato T, Nakanishi M, Kim M, Michalski J, Nelson AJ, Farid M, Basma H, et al: Prostaglandin E switches from a stimulator to an inhibitor of cell migration after epithelial-to-mesenchymal transition. Prostaglandins Other Lipid Mediat 116-117: 1-9, 2015.
25. Pino MS, Nawrocki ST, Cognetti F, Abruzzese JL, Xiong HQ and McConkey DJ: Prostaglandin E2 drives cyclooxygenase-2 expression via cyclic AMP response element activation in human pancreatic cancer cells. Cancer Biol Ther 4: 1263-1269, 2005.

26. Brouxhon S, Kyrkanides S, O'Banion MK, Johnson R, Pearce DA, Centola GM, Miller JN, McGrath KH, Erdle B, Scott G, et al: Sequential down-regulation of E-cadherin with squamous cell carcinoma progression: Loss of E-cadherin via a prostaglandin E2-EP2 dependent posttranslational mechanism. Cancer Res 67: 7654-7664, 2007.

27. Díaz-Muñoz MD, Osma-García IC, Fresno M and Iniguez MA: Involvement of PGE2 and the cAMP signalling pathway in the up-regulation of COX-2 and mPGES-1 expression in LPS-activated macrophages. Biochem J 443: 451-461, 2012.

28. Liou JY, Ellent DP, Lee S, Goldsby J, Ko BS, Matijevic N, Huang JC and Wu KK: Cyclooxygenase-2-derived prostaglandin e2 protects mouse embryonic stem cells from apoptosis. Stem Cells 25: 1096-1103, 2007.

29. Niho N, Kitamura T, Takahashi M, Mutoh M, Sato H, Matsuura M, Sugimura T and Wakabayashi K: Suppression of azoxymethane-induced colon cancer development in rats by a cyclooxygenase-1 selective inhibitor, mofezolac. Cancer Sci 97: 1011-1014, 2006

30. Kitamura T, Itoh M, Noda T, Matsuura M and Wakabayashi K: Combined effects of cyclooxygenase- 1 and cyclooxygenase- 2 selective inhibitors on intestinal tumorigenesis in adenomatous polyposis coli gene knockout mice. Int J Cancer 109: 576-580, 2004.

31. Fernández-Martínez AB and Lucio-Cazaña J: Intracellular EP2 prostanoid receptor promotes cancer-related phenotypes in PC3 cells. Cell Mol Life Sci 72: 3355-3373, 2015.

32. Sato T, Konomi K, Fujii R, Aono H, Aratani S, Yagishita N, Araya N, Yudoh K, Beppu M, Yamano Y, et al: Prostaglandin EP2 receptor signalling inhibits the expression of matrix metalloproteinase 13 in human osteoarthritic chondrocytes. Ann Rheum Dis 70: 221-226, 2011.

33. Rinn JL and Chang HY: Genome regulation by long noncoding RNAs. Annu Rev Biochem 81: 145-166, 2012.

34. Brosius J: Waste not, want not-transcript excess in multicellular eukaryotes. Trends Genet 21: 287-288, 2005.

35. Pollard KS, Salama SR, King B, Kern AD, Dreszer T, Katzman S, Siepel A, Pedersen JS, Bejerano G, Baertsch R, et al: Forces shaping the fastest evolving regions in the human genome. PLoS Genet 2: e168, 2006.

36. Seok J, Warren HS, Cuenca AG, Mindrinos MN, Baker HV, Xu W, Richards DR, McDonald-Smith GP, Gao H, Hennessy L, et al: Genomic responses in mouse models poorly mimic human inflammatory diseases. Proc Natl Acad Sci USA 110: 3507-3512, 2013.

37. Bastien L, Sawyer N, Grygorczyk R, Metters KM and Adam M: Cloning, functional expression, and characterization of the human prostaglandin E2 receptor EP2 subtype. J Biol Chem 269: 11873-11877, 1994. 